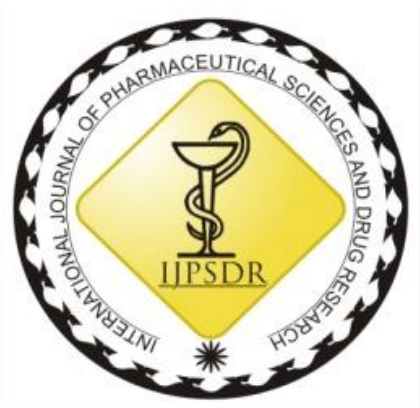

ISSN: 0975-248X

RESEARCH ARTICLE CODEN (USA): IJPSPP

$(\mathrm{cc})$ EY-NC-SA

\title{
A Fission Yeast Bioassay for Rapid Screening for Antiproliferative Agents from Bauhinia variegata and Leptadenia reticulata
}

\author{
P. A. Vyas ${ }^{1 *}$, V. J. Braganza ${ }^{2}$ \\ ${ }^{1}$ Department of Biochemistry and Forensic Science, University School of Science, Gujarat University, Navrangpura, \\ Ahmedabad-380009 Gujarat, India \\ ${ }^{2}$ Xavier Research Foundation, Loyola Centre for Research and Development, St. Xavier's College Campus, Navrangpura, \\ Ahmedabad-380009, Gujarat, India
}

Copyright (c) 2019 P. A. Vyas et al. This is an open access article distributed under the terms of the Creative Commons AttributionNonCommercial-ShareAlike 4.0 International License which allows others to remix, tweak, and build upon the work non-commercially, as long as the author is credited and the new creations are licensed under the identical terms.

\begin{abstract}
The aim of the present study was to evaluate the antiproliferative activity of crude extracts from leaves of Bauhinia variegata and Leptadenia reticulata using fission yeast Schizosaccharomyces pombe as a model. The crude extracts of both plants were prepared by three experimental conditions $\left(25^{\circ} \mathrm{C}\right.$, elevated temperature and ultrasound waves) and four solvent systems [Water, Methanol, Water: Methanol (1:1) and Chloroform: Methanol (1:1)]. MTT assay was performed for estimating the cell viability and the results were expressed as \% growth inhibition. Overall based on the MTT assay performed on yeast cells, Water: Methanol, Methanol and Water extracts showed higher antiproliferative activity than the positive control (Paclitaxel) in a dose-dependent manner. For Bauhinia variegata and Leptadenia reticulata, methanol extract $\left(25^{\circ} \mathrm{C}\right.$ temperature \& elevated temperature, respectively) exhibited highest inhibition which was approximately $80 \%$. In conclusion, this study has indicated that Bauhinia variegata and Leptadenia reticulata extracts possess strong antiproliferative activity. Furthermore, it could act as a potential source for identifying new molecules with chemotherapeutic potential against cancer.
\end{abstract}

Keywords: Medicinal plants, Fission yeast, S. pombe, Antiproliferative activity, MTT Assay.

DOI: 10.25004/IJPSDR.2019.110620

Int. J. Pharm. Sci. Drug Res. 2019; 11(6): 405-408

*Corresponding author: Ms. P. A. Vyas

Address: Department of Biochemistry and Forensic Science, University School of Science, Gujarat University, Navrangpura, Ahmedabad-380009 Gujarat, India

Tel.: +91-9908124092

E-mail $\bowtie$ : vyas.priya.a@gmail.com

Relevant conflicts of interest/financial disclosures: The authors declare that the research was conducted in the absence of any commercial or financial relationships that could be construed as a potential conflict of interest.

Received: 13 October, 2019; Revised: 12 November, 2019; Accepted: 15 November, 2019; Published: 30 November, 2019

\section{INTRODUCTION}

As per World Health Organization, around $70-95 \%$ of the population in developing countries rely upon drugs derived from medicinal plants to meet their primary healthcare needs. ${ }^{[1-2]}$ Medicinal plants have played an important role in pharmacological research and drug development as they are known to provide bioactive compounds as well as lead materials for synthesis of new drugs. ${ }^{[3]}$ More importantly, medicinal plants have made significant contribution in the discovery and development of anticancer agents. Some of the wellknown examples of medicinal plant derived anticancer drugs are Camptothecin, Podophyllotoxin and Paclitaxel. [4] Therefore, exploring the potential of 
different medicinal plants as a source of new anticancer agents based on their traditional uses could lead to discovery of new molecules.

Bauhinia variegata Linn (Caesalpiniaceae) has been used in treating bronchitis, leprosy, tumors and ulcer. ${ }^{[5-6]}$ Also, chemopreventive, anticarcinogenic and antimutagenic potentials of the plant has been reported. ${ }^{[7-8]}$ Leptadenia reticulata Wight \& Arn (Asclepiadaceae) possesses various pharmacological activities like antibacterial [9], antifungal [10], analgesic, antiinflammatory, anti-lipoxygenase. [11] Also, anticarcinogenic potential of the ethanolic extracts have been reported against Dalton's Ascitic Lymphoma. [12] In the present study, yeast was used as a model organism as it has significant similarities to mammalian cells at the molecular and organelle level. ${ }^{[13]}$ It has relatively short doubling time and thus allows examining exposure to drugs over many population doublings. ${ }^{[14]}$ Fission yeast has served as an excellent model organism for studying processes like cell-cycle control, DNA repair and recombination, mitosis and meiosis, and the checkpoint controls important for genome stability. ${ }^{[15]}$ It is widely known that pathways related to cancer-related and genes corresponding to those pathways are conserved between yeast and humans. ${ }^{[16]}$ As a tool for anticancer drug screening, fission yeast Schizosaccharomyces pombe has gained acceptance because of extensive conservation of cellular processes between yeast and mammalian cells. [14] $S$. pombe as a model offers several advantages such as: a) it has a cell division pattern similar to mammalian cells [17]; b) basic mechanisms such as DNA metabolism and cell proliferation control are conserved between yeast and human cells [18]; c) biological patterns that are comparable to human cancer cells. ${ }^{[17]}$ Hence, our study used fission yeast mutant having an altered cell cycle to perform a pilot screen on a range of extracts prepared from the plant. Because of its altered cell cycle, this mutant has rapid proliferation rate and hence it mimics a cancer cell.

\section{MATERIALS AND METHODS}

The leaves of Bauhinia variegata and Leptadenia reticulata was collected from Xavier Residence c/o St. Xavier's College Campus, Ahmedabad. The plant was authenticated by Botanist Dr. Hitesh Solanki from Botany Department of Gujarat University. Leaves were thoroughly washed with running tap water to remove the dirt particles followed by distilled water and were then shade dried. The dried leaf was then crushed into fine powder and subjected to extraction. The crude extracts were prepared by using three experimental conditions and four solvent systems. The purpose of using different methods and solvents was to ensure effective extraction of phytochemicals from plant material, generation of range of phytochemicals and identifying best combination of experimental conditions and solvent for extraction. The powder to solvent (w/v) ratio was kept 1:10. [19] The elevated temperature extraction was carried out in a hot water bath below the boiling point of the respective solvents used for extraction. The temperature used for each solvent system was: (i) Water $\left(90^{\circ} \mathrm{C}\right)$; ii) Methanol $\left(55^{\circ} \mathrm{C}\right)$; iii) Water: Methanol $\left(65^{\circ} \mathrm{C}\right)$; iv) Chloroform: Methanol $\left(50^{\circ} \mathrm{C}\right)$. Sonication was performed using ultra sound waves with aid of bath sonicator. [20]

For elevated temperature and sonication extraction, one gram powder was taken in stoppered tube and $10 \mathrm{ml}$ of solvent was added to it which was then incubated in a hot water bath or bath sonicator for one hour. At the end of the incubation period, the filtrate was collected in a pre-weighed beaker. The extraction was performed in this manner until the solvent became colourless. In case of cold extraction (i.e. $25^{\circ} \mathrm{C}$ temperature), the solvents were changed every 24 hours and constant agitation was provided at $100 \mathrm{rpm}$. [21] The extracts were filtered using Whatman no. 1 filter paper. The collected filtrate was pooled and evaporated to dryness until a constant weight was achieved. Then stocks of the extract at concentration of $100 \mathrm{mg} / \mathrm{ml}$ were prepared in DMSO and stored at $-20^{\circ} \mathrm{C}$ until further use.

Determination of antiproliferative activity using Schizosaccharomyces pombe

Schizosaccharomyces pombe was procured from the National Collection of Yeast Cultures (Accession No. NCYC 1683). Yeast cells were cultured in YPD medium (1\% Yeast extract, 2\% Peptone and 2\% Dextrose) and incubated overnight at $25^{\circ} \mathrm{C}$. The antiproliferative activity of the extracts was measured by 3-(4, 5dimethylthiazol-2yl) 2, 5- diphenyltetrazolium bromide (MTT) assay. Briefly, the optical density (OD) of an overnight incubated culture was read at $600 \mathrm{~nm}(0.1$ OD equates to $\sim 1.5-2 \times 10^{6}$ cells $/ \mathrm{mL}$ ) to measure culture biomass. ${ }^{[22]}$ The culture was diluted to achieve desired cell concentration and the cells (4000 cells/well) were seeded to a 96 well plate. The cells were treated with different concentrations of the extracts $(250,500$ and $1000 \mu \mathrm{g} / \mathrm{ml}$ ) from stocks and incubated for 24 hours. Paclitaxel was used as a positive control in the experiment. [23] DMSO was used as a vehicle control and untreated cells were taken as negative control. Following the incubation period, MTT dye $(5 \mathrm{mg} / \mathrm{ml})$ was added to the wells and incubated for four hours in the dark. The formazan crystals formed at the end of the incubation period were dissolved in DMSO. The absorbance was read at $570 \mathrm{~nm}$ using Multiskan Go microplate reader. The percentage cell viability was calculated using the following formula

$\%$ Cell Viability $=\left[\left(\mathrm{OD}_{\text {sample }}-\mathrm{OD}_{\text {blank }}\right) /\left(\mathrm{OD}_{\text {control }}-\mathrm{OD}_{\text {blank }}\right)\right] \times 100$

Statistical Analysis

The results were expressed in terms of percentage growth inhibition. Non-linear regression analysis was used to calculate the $\mathrm{IC}_{50}$ values. All the experiments were performed in triplicates and the results are shown below as Mean \pm Standard deviation. 


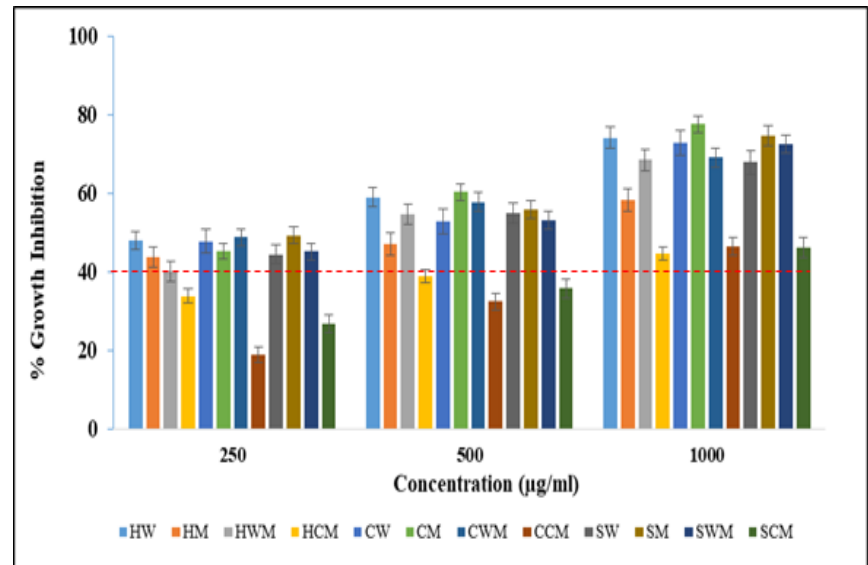

Fig. 1: Growth inhibitory effect of Bauhinia variegata Linn crude extracts on S. pombe (NCYC 1683)

The cells were treated with different concentration of extracts for 24 hrs. The \% growth inhibition was represented as Mean \pm SD $(n=3)$. The crude extracts were prepared at Elevated temperature $(\mathrm{H}), 25^{\circ} \mathrm{C}$ (C) and Sonication (S) method. The solvent system used was Water (W); Methanol (M); Water: Methanol (WM); and Chloroform: Methanol (CM). In the graph abbreviation used represents method $(\mathrm{H}, \mathrm{C}$ and $\mathrm{S})$ and solvent system $(\mathrm{W}, \mathrm{M}, \mathrm{WM}$ and $\mathrm{CM})$. The dotted line represents cell growth inhibition $(40 \%)$ by positive control Paclitaxel.

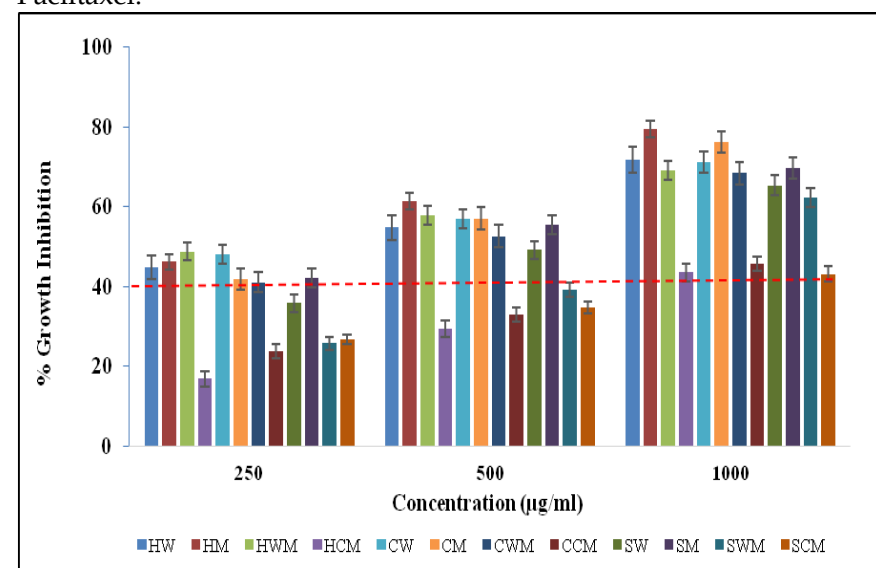

Fig. 2: Growth inhibitory effect of Leptadenia reticulata Wight \& Arn crude extracts on S. pombe (NCYC 1683)

The cells were treated with different concentration of extracts for 24 hrs. The \% growth inhibition was represented as Mean \pm SD $(n=3)$. The crude extracts were prepared at Elevated temperature $(\mathrm{H}), 25^{\circ} \mathrm{C}$ (C) and Sonication (S) method. The solvent system used were Water (W); Methanol (M); Water: Methanol (WM); and Chloroform: Methanol $(\mathrm{CM})$. In the graph abbreviation used represents method ( $\mathrm{H}, \mathrm{C}$ and $\mathrm{S})$ and solvent system $(\mathrm{W}, \mathrm{M}, \mathrm{WM}$ and $\mathrm{CM})$. The dotted line represents cell growth inhibition $(40 \%)$ by positive control Paclitaxel.

\section{RESULTS}

For evaluating the antiproliferative activity of crude extracts using $S$. pombe, fresh culture having optical density 0.8 was used for the experiment. The crude extracts of Bauhinia variegata Linn and Leptadenia reticulata (Retz.) Wight \& Arn were analysed for decrease in cell viability using the MTT assay in mutant yeast. Cell viability can be correlated to antiproliferative effect of the extract. If the extract is cytotoxic it will decrease the number of viable cells compared to that in the control. All the 24 extracts (12 extracts per plant) were screened at concentrations of 250, 500 and $1000 \mu \mathrm{g} / \mathrm{ml}$ on S. pombe (NCYC 1683). Figure 1 \& 2 represent the percentage cell growth inhibition of S. pombe treated with crude extracts of all three plants at different doses. It was clearly observed that the decrease in the growth of yeast cells was dose dependent. Moreover, the growth inhibition capacity of the extracts was compared with that of the standard drug Paclitaxel used in the treatment of cancer. When cells were treated with Paclitaxel at $2.5 \mathrm{~nm}$ concentration the percentage growth inhibition of yeast cells was approximately $40 \%$. Therefore, in our study, we have chosen $40 \%$ cell growth inhibition as a screening criteria for crude extracts. The crude extracts showing inhibition higher than $40 \%$ were considered to have potential cytotoxic activity and were selected for secondary screening on cancer cell lines.

For Bauhinia variegata (Fig. 1), the antiproliferative activity of extracts prepared at elevated temperature ranged from $33 \%$ to $74 \%$ after incubation of 24 hours. The antiproliferative activity of extracts prepared at $25^{\circ} \mathrm{C}$ temperature ranged from $18 \%$ to $78 \%$. Next, the antiproliferative activity of extracts prepared at sonication ranged from $26 \%$ to $75 \%$. Among the four solvent systems used for extraction, it was observed that the water extracts showed highest growth inhibition whereas chloroform: methanol extracts showed lowest inhibition. Out of the three treatment methods used for extraction, $25^{\circ} \mathrm{C}$ temperature showed highest inhibition followed by elevated extraction and lowest was observed in sonication extraction.

For Leptadenia reticulata (Fig. 2), the antiproliferative activity of extracts prepared at elevated temperature ranged from $16 \%$ to $79 \%$ after incubation of 24 hours. The antiproliferative activity of extracts prepared at $25^{\circ} \mathrm{C}$ temperature ranged from $23 \%$ to $76 \%$. Next, the antiproliferative activity of extracts prepared at sonication ranged from $25 \%$ to $70 \%$. Among the four solvent systems used for extraction, it was observed that the methanol extracts showed highest growth inhibition whereas chloroform: methanol extracts showed lowest inhibition. Out of the three treatment methods used for extraction, elevated temperature extraction showed highest inhibition followed by $25^{\circ} \mathrm{C}$ and lowest was observed in sonication extraction.

\section{DISCUSSION}

In the present study, as a preliminary screening the crude extracts were evaluated for its antiproliferative activity using a mutant fission yeast Schizosaccharomyces pombe strain using 1-(4,5-dimethylthiazol-2-yl)-3,5diphenyltetrazolium bromide (MTT) assay. [24] This mutant yeast has modified cdc gene, and thus, has an altered cell cycle. ${ }^{[18]}$ An altered cell cycle gene would cause a loss in cell cycle regulation which is often the situation in any cancer cell. Thus, by utilizing this mutant yeast one can identify crude extracts with potential antiproliferative activity from the range of extracts of the three plants prepared in our study. Similar studies have been reported where mutant yeast was used as screening tool for identifying bioactive molecules. In a study, a bioactive compound known as 
2', 4' - dihydroxychalcone from leaves of Corema album was identified using S. pombe. [18] Additionally, the mechanism of action of a known phytochemical Plumbagin (a well-known plant derived anticancer compound) was elucidated using $S$. pombe. [17] Furthermore, cytotoxic effect of various extracts from Phyllanthus emblica L. ${ }^{25]}$ and Nyctanthes arbortristis L. [26] were tested using $S$. pombe. Based on these studies, we tested the antiproliferative potential of our crude extracts on $S$. pombe.

From this screening, we identified that for Bauhinia variegata Linn and Leptadenia reticulata the water, methanol, and water: methanol extracts of all three methods showed higher growth inhibition as compared to Paclitaxel (a chemotherapeutic drug used for cancer treatment). The difference in the antiproliferative effects between different extracts may have resulted from the different phytoconstituents and their concentrations contained in the extracts due to the sensitivity to the solvent used and mode of extraction. On the basis of this pre-screen extracts with potential cytotoxic activity can be selected for secondary screening against panel of cancer cell lines.

\section{ACKNOWLEDGEMENTS}

This work was made possible and supported by internal grants of the Xavier Research Foundation. The author also thanks the Foundation for the fellowship awarded to her during the tenure of this study.

\section{REFERENCES}

1. Bansal G, Suthar N, Kaur J, Jain A. Stability Testing of Herbal Drugs: Challenges, Regulatory Compliance and Perspectives. Phyther Res. 2016; 30(7): 1-13.

2. Robinson MM, Zhang X. The World Medicines Situation 2011 Traditional Medicines: Global Situation, Issues and Challenges. Geneva; 2011.

3. Alam G, Mishra AK. Traditional and Modern Approaches for Standardization of Herbal Drugs: A Review. Acta Biomed Sci. 2017; 4(1): 40-55.

4. Oberlies NH, Kroll DJ. Camptothecin and Taxol: Historic Achievements in Natural Products Research. J Nat Prod. 2004; 67(2):129-135.

5. Mishra A, Sharma AK, Kumar S, Saxena AK, Pandey AK. Bauhinia variegata Leaf Extracts Exhibit Considerable Antibacterial, Antioxidant, and Anticancer Activities. Biomed Res Int. 2013; 2013: 1-10.

6. Rajkapoor B, Jayakar B, Murugesh N, Sakthisekaran D. Chemoprevention and cytotoxic effect of Bauhinia variegata against $\mathrm{N}$-nitrosodiethylamine induced liver tumors and human cancer cell lines. J Ethnopharmacol. 2006; 104:407-409.

7. Pandey S, Agrawal RC. Effect of Bauhinia variegata Bark Extract on DMBA-Induced Mouse Skin Carcinogenesis: A Preliminary Study. Glob J Pharmacol. 2009; 3(3): 158-162.

8. Rajkapoor B, Jayakar B, Murugesh N. Antitumour activity of Bauhinia variegata on Dalton's ascitic lymphoma. J Ethnopharmacol. 2003; 89: 107-109.
9. Kalidass C, Glory M, Borgio F, Manickam VS. Antibacterial Activity of Leptadenia reticulata (Retz.) Wight. \& Arn. (Asclepidaceae). Anc Sci Life. 2009; 28(4): 10-12.

10. Mishra MK, Tiwari P, Dash DK, Jadon RS, Ghosh G, Barik BB. Antifungal activity of Leptadenia reticulata Wight and Arn. aerial parts. Int J Phytomedicine. 2010; 2: 172-176.

11. Mohanty SK, Swamy MK, Middha SK, Prakash L, Subbanarashiman B, Maniyam A. Analgesic, Antiinflammatory, Anti- lipoxygenase activity and Characterization of Three Bioactive Compounds in the Most Active Fraction of Leptadenia reticulata (Retz.) Wight \& Arn.A Valuable Medicinal Plant. Iran J Pharm Res. 2015; 14(3): 933-942.

12. Sathiyanarayanan L, Arulmozhi S, Chidambaranathan N. Anticarcinogenic activity of Leptadenia reticulata against Dalton's Ascitic Lymphoma. Iran J Pharmacol Ther. 2007; 6(2): 133-135.

13. Kiruthika B, Padma PR. Zea mays leaf extracts protect Saccharomyces cerevisiae cell against oxidative stress-induced cell death. J Acute Med. 2013; 3: 83-92.

14. Simon JA, Bedalov A. Yeast as a model system for anticancer drug discovery. Nat Rev. 2004; 4: 1-8.

15. Perego P, Jimenez GS, Gatti L, Howell SB, Zunino F. Yeast Mutants as a Model System for Identification of Determinants of Chemosensitivity. Pharmacol Rev. 2000; 52(4): 477-491.

16. Gao G, Chen L, Huang C. Anti-cancer Drug Discovery: Update and Comparisons in Yeast, Drosophila, and Zebrafish. Curr Mol Pharmacol. 2014; 7: 44-51.

17. Lee J-HH, Yeon J-HH, Kim H, et al. The Natural Anticancer Agent Plumbagin Induces Potent Cytotoxicity in MCF-7 Human Breast Cancer Cells by Inhibiting a PI-5 Kinase for ROS Generation. PLoS One. 2012; 7(9): 1-10.

18. Sánchez-Picó Á, León-González AJ, Martín-Cordero C, Daga RR. Screening for natural anticancer agents using a fission yeast bioassay. Phytochem Lett. 2014; 8(1): 184-189.

19. Tiwari P, Kumar B, Kaur M, Kaur G, Kaur H. Phytochemical screening and Extraction - A Review. Int Pharm Sci. 2011; 1(1): 98-106.

20. Romanik G, Gilgenast E, Przyjazny A, Kamiński M. Techniques of preparing plant material for chromatographic separation and analysis. J Biochem Biophys Methods. 2007; 70(2): 253-261.

21. Methods of Extraction and Chracterisation: Mammen D. In: Daniel DM, editor. Methods in Plant Chemistry and Economic Botany. Kalyani Publishers: New Delhi, 1991, p.122.

22. Petersen J, Russell P. Growth and the environment of Schizosaccharomyces pombe. Cold Spring Harb Protoc. 2016; (3): 210-226

23. Schiller JH, Harrington D, Belani CP, et al. Comparison of Four Chemotherapy Regimens for Advanced Non-Small-Cell Lung Cancer. N Engl J Med. 2002; 346(2): 92-98.

24. Sánchez NS, Königsberg M. Using Yeast to Easily Determine Mitochondrial Functionality with 1-(4,5-dimethylthiazol-2yl)-3,5-diphenyltetrazolium Bromide (MTT) Assay. Biochem Mol Biol Educ. 2006; 34(3): 209-212.

25. Desai K, Braganza V. Cytotoxic Activity and Phytochemical Investigation of Phyllanthus emblica L. Leaves. Int J Pharm Sci Res. 2016; 7(5): 2015-2019.

26. Vyas P, Braganza V. A Preliminary Study on the Antiproliferative Activity of Nyctanthes arbortristis Leaf Extracts Using Fission Yeast as a Model. Int J Curr Adv Res. 2018; 7(3(J)): 11096-11101. 